\title{
TENDÊNCIAS DA PESQUISA EM ENFERMAGEM
}

\author{
Mariana Fernandes de Souza*
}

\section{Introdução}

A apenas oito anos do início do século XXI, com metas explícitas em frases como: "Saúde para todos no ano 2.000", "Enfermeiras como força social", "Unidade para a qualidade", entre outras, a desafiarem-nos, sentimos a necessidade de nos questionar sobre: o que fizemos ou estamos fazendo? Qual tem sido o resultado de nossa ação como profissionais da saúde? Tudo o que hoje sabemos melhor compreender e verbalizar corresponde a um melhor fazer, a um maior benefício para a saúde da população? Por certo que muito tem sido realizado por enfermeiros em várias frentes de trabalho; conquistas houveram com certeza. No entanto, ao pensarmos sobre os problemas de saúde da população brasileira, é forçoso concluir que muito está por ser feito e que os desafios são imensos. Grande parte da população precisa de coisas aparentemente tão simples que nos custa imaginar tanta dificuldade em conseguir, tais como: água limpa para beber, alimento para se nutrir, ar puro para respirar, local adequado para se abrigar e trabalho para fazer. Há carência de meios para sobreviver e para saber viver. Por outro lado, existem os problemas característicos de áreas desenvolvidas e industrializadas que também precisam de atenção.

Discutir as tendências da pesquisa em Enfermagem é um assunto complexo, que demanda inserção em um quadro contendo ambigüidades e problemas próprios da situação brasileira como um todo. Conduzir a discussão nesse cenário é tarefa diffcil. Cremos que a pesquisa, seriamente conduzida, pode oferecer pistas para a ação de enfermagem. Porém, inserir a ação de pesquisar em enfermagem no atendimento das necessidades de saúde da população brasileira leva a questões relevantes como: focalizar as tendências da pesquisa para os problemas das áreas mais desenvolvidas ou para os das áreas de pobreza? E possivel conciliar esses pontos opostos? A enfermagem brasileira conta com os instrumentos e as condições necessárias ao exercício da pesquisa? $O$ tratamento do tema obriga-nos a uma tomada de posição sobre o caminho a ser seguido.

O enfermeiro atua nesses cenários desiguais, portanto, a atividade de pesquisa deve estar voltada para a atenção aos reclamos das recessidades de saúde da área onde ele exerce a profissão; tal fato nos leva, inevitavelmente a pensar em pesquisar para um agir em enfermagem que contribua para o alcance das metas ainda não realizadas e pesquisar para que a sociedade brasileira não fique a re-

\footnotetext{
- Enfermeira. Professora Titular do Departamento de Enfermagem da Escola Paulista de Medicina.
} 
boque de um mundo que se transforma em ritmo acelerado. Não conseguindo segmentar esse contexto cheio de contrastes e conscientes das dificuldades em propormos de modo adequado as direçōes que a pesquisa em enfermagem deve tomar, tentaremos trazer, para discussão, aspectos desse contexto, consideraçōes gerais sobre a enfermagem e a inserção dos mesmos em um referencial que poderá nos dar base para um aprofundamento do tema.

\section{Contexto}

Não temos a pretensão de descrever de modo abrangente a dimensão da realidade natural, económica e social do Brasil. Procuraremos estudar aspectos dessa realidade que escolhemos, como ponto de partida para compreensão de fatos que nos permitam uma discussão melhor fundamentada.

O Brasil, como sabemos, é na maior parte de sua extensa área, privilegiado com uma natureza rica e exuberante, muito longe ainda de ser totalmente explorada, cuidada e defendida. Como acontece em todo o globo, as agressões e a poluição do eco-sistema aqui também se fazem presentes, o que reflete na saúde da população, de maneira mais danosa para os mais desprotegidos, isto é, os pobres de bens materiais, conhecimentos e capacidade de defesa. Nosso pals se situa como periférico no sistema económico. É um país em desenvolvimento, com ilhas de primeiro mundo e muito de subdesenvolvimento.

A situação de saúde da população brasileira é complexa. Segundo ARAUJO (1992), verifica-se no país " uma polarização epidemiológica com a existência simultânea de elevadas taxas de morbidade e mortalidade por doenças crônico-degenerativas e de elevadas taxas de incidência e prevalência de doenças infecciosas e parasitárias". Ainda afirma o mesmo autor que se observa "ao lado da polarização entre tipos de agravos à saúde (doenças crónico-degenerativas versus doenças infecciosas e parasitárias), um outro tipo de polarização, a geográfica, significando a existência de regióes com padróes de saúde comparáveis aos dos países desenvolvidos e regióes com índices de mortalidade comparáveis aos dos países mais pobres do hemisfério sul. Existe ainda a polarização social que se manifesta pelos desniveis nos indicadores de mortalidade e morbidade entre diferentes grupos populacionais, dentro de uma mesma região, estado ou cidade. Ela é uma expressão das desigualdades de renda, da carência de alimentaçáo, moradia, saneamento, educação e, também, da dificuldade de acesso aos serviços de saúde". Acrescentam-se a essa situaçăo descrita, os problemas relacionados aos acidentes de trânsito e de trabalho, os de saúde mental e os relativos ao aumento da longevidade. A elaboraçáo e implementação da política de saúde para o Brasil apresenta muitos desafios relacionados à priorização da saúde e à reorganização do sistema, caminhando para a descentralizaçăo. MENDES (1992) ao tratar da municipalização da saúde no Brasil, julga haver uma luta política, ideológica e técnica no ‘ampo da saúde, e aparente consenso de discurso e dissenso na prática social oriundo das várias formas como os sujeitos decodificam a questão da municipalizaçăo da saúde.

\section{Consideraçōes Gerais sobre a Enfermagem Brasileira}

O progresso da enfermagem tem sido feito à custa de muita luta contra preconceitos e detentores de poder. Assim, o ingresso ao nível universitário, aos 
cursos de pós-graduação, a institucionalização da profissăo vem se fazendo paulatinamente e de modo árduo. Existem no momento no pais 55.335 enfermeiros para um apopulação de cerca de 150 milhões de habitantes. A força de trabalho em enfermagem, como se sabe é constituída por elementos de várias categorias. Além dos enfermeiros, existem 41.597 técnicos, 156.169 auxiliares de enfermagèm e 52.234 atendentes autorizados em São Paulo (mas o número total é muito maior)* ${ }^{*}$ O pessoal de enfermagem representa $50 \%$ dos trabalhadores da área de saúde. Essa alta porcentagem deveria traduzir na realidade a importância e o reconhecimento social da profissãc. No entanto, existem fatores internos e externos que se articulam e constituem forças propulsoras ou bloqueadoras da trajetoria profissional. A problemática é bem conhecida. Relacionaremos a seguir alguns problemas.

As diferenças do nível educacional das pessoas que se dedicam à enfermagem enfraquece o grupo como agente coletivo que conjugue esforços para o alcance de metas comuns; dificulta a consciência de clase. E também um fator de desequilíbrio de relaçóes entre o grupo e deste com outros profissionais da saúde, o que reflete no relacionamento com a população.

$\mathrm{Na}$ área, o grande contingente é de mulheres; estas sáo alvo, ainda, de muita discriminação social quanto ao sexo e ao trabalho. Os baixos salários obrigam ao trabalho em mais de um emprego. No trabalho frequentemente as condições não são boas, levando perigo à população e extremo desgaste de quem trabalha. Há pouca acessibilidade às oportunidades de crescimento pessoal. Há tambem, falta de reconhecimento da enfermagem como atividade essencial nas instituições de saúde. Apesar da grande responsabilidade que envolve as ações de enfermagem, há limitações e falta de autonomia. O maior mercado de trabalho continua sendo o hospital urbano onde o cuidado é o curativo; não há operacionalização dos níveis de atendimento propostos hoje como os mais adequados.

Não é possível, no entanto, a assistência à saúde sem a participação da enfermagem.

A consciência disso, o compromisso aliado ao trabalho, podem nos levar a ser "uma força social" na promoção da saúde.

\section{Tendências da Pesquisa em Enfermagem}

As reflexס̃es feitas nos itens anteriores são fundamentos para propormos a direção que, a nosso ver, a pesquisa em enfermagem poderia seguir. Os problemas da realidade em que vivemos e atuamos é que nos fornecerão as questões para pesquisar e obter informações para um cuidado mais efetivo, a fim de formularmos o papel específico do enfermeiro no sistema de cuidado à saúde, questóes estas que vão mudando à medida em que a sociedade se transforma e em que novos conhecimentos e novas tecnologias surgem.

Seguiremos, como um referencial que nos guie na análise e interpretação de dados do contexto e da enfermagem brasileira e na sugestão de direções para pesquisas, o trabalho sociológico de SROUR (1990) sobre as relações sociais, do qual utilizaremos parte.

- Dados do UPD - COFEN, 30 de setembro, 1992. 
Síntese do referencial - Sem a manutenção de vínculos, de relações uns com os outros, dificilmente os homens conseguiriam sobreviver. "A produção das nossas condiçőes de existência, a transformação da natureza para a satisfação das nossas necessidades é sempre uma obra coletiva ". Todas as pessoas são, portanto, agentes sociais, isto é, membros de uma sociedade, que mantêm relações uns comı os outros. Os agentes sociais podem ser agentes individuais (indivíduos) e agentes coletivos (coletividades), segundo as situações vividas. "Cada um de nós é, simultaneamente, agente individual e expressão ativa de vários agentes coletivos" (coletividades a que pertenço). As relaçóes sociais comportam divisões ou formas que são as dimensões. Estas são o espaço onde se processam produções, ou seja, processos de transformação e de apropriação no mundo. As dimensões sáo: económica, política e simbolica.

Dimensão económica - "os agentes coletivos garantem sua sobrevivência física através da produção de bens e serviços materiais".

Dimensão política - "os agentes coletivos organizam e regulam suas atividades: num dado território ou numa dada unidade social, através da tomada de implementação de decisóes que assumem um caráter imperativo, obrigatório para todos".

Dimensão simbólica - "os agentes coletivos pensam o mundo através da produção de mensagens, discursos, idéias, tecnologia, procedimentos".

As dimensões sociais, para efeito didático, comportam esferas, divisões nas quais ocorrem produçóes particulares de bens e serviços. As esferas económicas são: produção, troca, distribuição, conservação. As esferas políticas são: segurança, administração, justiça, deliberação. As esferas simbólicas são: ideologia, ciência, arte, têcnica. Em cada uma dessas esferas são realizadas atividades por determinados trabalhadores.

\section{"Províncias" Sociais}

\section{Dimensáo}

econômica

política

simbólica
Transformaçáo

produto material

regulação social

representaçăo imaginária
Apropriaçáo

produtos

poderes

saberes

(SROUR, 1990, p.45)

Produção e consumo - A produção existe para o consumo. Toda socieda-de, embora o faça por formas diferentes, tem necessidade de alimentação, abrigo, etc. (dimensão económica), de organizar seus empreendimentos coletivos (dimensão política), de planejar suas atividades e transmitir conhecimentos, obras culturais e técnicas (dimensão simbólica). O que se produz existe para o consumo e este possibilita a reproduçăo da própria sociedade. $O$ consumo possibilita que os agentes coletivos e individuais reproduzam suas atividades. Re-produção produção nova, que o consumo facultou. É no processo de produpão que se pode identificar os agentes coletivos, seus interesses e as contradições. "Dependendo das relaçōes sociais existentes, a apropriação dos produtos se dá de forma equitativa ou desigual". 
A enfermagem está localizada na dimensão simbólica e na esfera técnica. Sua atividade é a de geração de procedimentos, de maneiras de fazer, de aplicação de tecnologias.

Os bens simbolicos, ainda que utilizem meios materiais, são de consumo mental, simbólico (a atividade simbólica nåo produz um bem que se pode destacar materialmente da propria atividades que o gera).

A localizaçăo em dimensóes significa que os agentes sociais exercem as atividades proprias destas como profissão, como meio de vida. No entanto, participam das outras, e a dimensåo economica permeia fortemente a simbolica e a política. Na realidade o social é uno, mas internamente diferenciado.

SROUR (1990) afirma que os conceitos aqui utilizados são gerais e abstratos, săo ferramentas de trabalho para pensar o mundo. Para ter o sentido efetivo é necessário aplicá-los a situações concretas.

\section{Processo de Produçáo em Enfermagem}

Vamos situar o enfermeiro na dinâmica de suas atividades, ou seja, no seu processo de trabalho. Focalizaremos sua ação nas organizaçठes, portanto onde se darão as relaçóes com outros agentes coletivos. A assitência de enfermagem é parte da assistencia à saúde, que é realizada por vários tipos de técnicos (os que produzem e exercem saberes). É um trabalho onde se dá divisão técnica, e, no caso da enfermagem, ainda há a divisăo interna dos elementos poí categorias quanto à capacitação para o exercício e a geraçăo do saber. Inicialmente, consideramos o enfermeiro como profissional qualificado que tem o dominio dos instrumentos e do exercício do saber para gerar bens. $\mathrm{Na}$ área hospitalar, ele trabalha cuidando diretamente dos pacientes ou administrando o cuidado. A fim de cuidar do paciente ele deverá executar procedimentos para cumprir a prescriçăo médica, e, neste aspecto, o médico é que tem a autoridade. Mas, o enfermeiro não é mero executor; ao realizar o procedimento técnico, ele exercita sua capacidade de interação, observação, avaliaçăo, julgamento, tomada de decisões. Além de cumprir a prescriçăo médica, o enfermeiro pode gerar procedimentos (mensagens e saberes) para promover o conforto, ajudar o paciente a cooperar com o tratamento, a enfrentar a situaçăo de doença, a diminuir o estresse para educaçăo e prevenção de enfermidades. Administrando o cuidado, o enfermeiro tambem cumpre prescriçőes médicas, observa regulamentos e normas emanadas de administradores da instituição. Igualmente ao cuidado direto, ele também exerce seu saber na organização e gerência da assistência ao paciente, bem como coordena atividades de provimento da unidade de internaçáo (materiais, equipamentos) e atividades de relação com outros setores da instituição.

No trabalho em ambulatório, nas unidades básicas de saúde (UBS), em que pesem as especificidades de atividades próprias da assistência à saúde comunitária, vamos considerar que tambem o enfermeiro administra e executa cuidados, repetindo-se situação semelhante à já descrita. É bom relembrar que no Brasil a atençăo à saúde é predominantemente curativa.

O enfermeiro exerce ainda, a funçăo de docência nas escolas de enfermagem. Seu papel ê o de transmitir mensagens, ensinar procedimentos e técnicas, gerar saber. 
Inerente às anteriormente descritas, está a atividade de pesquisa, por meio da qual o enfermeiro exercita e gera procedimentos, o "know-how" para a solução de problemas e enfim, para o consumo da população.

Emparelhando o que escrevemos acima, de modo resumido e linear, sobre onde e em que organizações o enfermeiro trabalha, com o que dissemos anteriormente sobre o contexto e a enfermagem brasileira, podemos procurar a direção em que os enfermeiros poderiam exercitar seus esforços de pesquisa. Nossa busca será dirigida aos seguintes pontos centrais: 1 ) relações da enfermagem com outros agentes coletivos; 2) instrumentos de trabalho e produção; 3 ) produção e consumo.

1) É normal que os agentes coletivos tenham interesses diferentes, contraditorios. Ao defender seus interesses eles entram em confronto, é isto que modifica as relações sociais. A contradição e o choque de interesses existem e não podem ser eliminados, pois não há como evitar que existam pólos opostos. $O$ necessário é que os interesses divergentes sejam passíveis de conciliação; que se confrontem e sejam encontrados denominadores comuns que possibilitem a coexistência.

O exercício da enfermagem se dá, entre nós, em situações de relações complexas, nem sempre cooperativas. Existem problemas nas relaçóes com outros profissionais da saúde, com a estrutura das instituições e com os próprios elementos que compóem a equipe de enfermagem.

- Há necessidade de investigações que nos forneçam dados concretos (condições de trabalho versus exigências) para que se organizem, se elaborem modelos de relacionamento que permitam ao enfermeiro desenvolver o seu trabalho com autonomia e reconhecimento correspondentes ao seu preparo e às responsabilidades inerentes à sua ação.

- Pesquisas para desenvolver estratégias de ação cooperativa entre enfermeiros e os demais componentes da equipe de enfermagem.

2) O exercício da enfermagem demanda instrumentos de trabalho adequados à sua finalidade. São os meios necessários a produção. A atividade técnica do enfermeiro, como já dissemos, supõe geração e propagação de procedimentos, aplicação de tecnologia. O enfermeiro produz saber e exerce este saber no seu trabalho. Os instrumentos de trabalho constituídos pelos equipamentos materiais são de extrema importância e, entre nós, sua carência e inadequação são frequentemente fonte de problemática séria. Vamos nos ater, porém, à geração e propagação de procedimentos, a produção e exercício do saber. Equivale à pergunta: que fazer para uma assistência de enfermagem que dé resultados positivos, nas instituiçôes de saúde e na comunidade? É uma questão crucial, abrangente, plena de problemas de pesquisa.

Algumas sugestões:

- Como administrar a assistência de enfermagem com os recursos disponíveis, de modo a possibilitar cuidar com qualidade e eficiência.

- Investigar meios de fortalecer a posição da enfermagem na estrutura das instituições de saúde.

- Pesquisas para melhorar e gerar procedimentos adequados aos problemas da realidade onde o enfermeiro desenvolve seu trabalho. 
Este item abrange procedimentos para situações simples e complexas, para instituições de poucos recursos e para as possuidoras de sofisticações e tecnologias de vanguarda.

- Pesquisas para remover práticas positivas de saúde (visando a polarizaçáo existente no país).

- Pesquisas relacionadas a grupos de risco.

- Estudos que forneçam dados, que criem estratégias contra os preconceitos e discriminação da mulher.

- Estudos que visem a promoção de oportunidades de educação continuada aos que trabalham em enfermagem.

- Pesquisas sobre estratégias para aumentar o reconhecimento do valor da enfermagem e para mudar as mensagens negativas sobre a carreira.

- Pesquisas de meios para fortalecer a autovalorização dos enfermeiros.

Os enfermeiros que trabalham na educação formal, ou seja, nas escolas de enfermagem, têm uma responsabilidade muito grande em relação à necessidade de refletir, de criticar os programas e métodos utilizados na formação de seus alunos. A escola, de modo geral, tem sido entre nós pressionada por conflitos inerentes à conjuntura atual. Qual é o modelo a ser adotado diante dos desequilíbrios sociais e regionais de nossa situação?

Em coerência com as idéias até agora desenvolvidas, é necessário buscar questóes que advêm do ambiente, de nosso mundo imediato. Com bae nos dados obtidos, elaborar os conteúdos e os objetivos do programa escolar, sem omitir de fazer projeções para o futuro. Isto equivale dizer que a escola de enfermagem deve adotar um paradigma dinâmico-dialógico. Nas proposições para o futuro, é necessário estar alerta para o que SANTOS (1990) descreve como a crise da ciência moderna e a transição para o paradigma emergente da ciência pós-moderna. As reflexões e especulações feitas por este autor sobre as características do conhecimento científico pós-moderno ajustam-se aos princípios e valores que a enfermagem tem preconizado.

3) Produção e consumo. O trabalho em saúde tem a especificidade de que as ações de prestação de serviços são nelas mesmas, produção e consumo. Assim, nossa ação de cuidar é direta para as pessoas. Supõe, é claro, a aceitação dos que são cuidados, mas os aspectos de competência profissional, dos limites de ação, da significação ética e social do nosso trabalho exigem reflexões e estudos:

- A quem estamos servindo? Como são as condiçõs em que se dão nossa ação?

-Quem está se beneficiando com nossa ação?

Para finalizar, não fizemos menções específicas, mas a dimensão simbólica está intimamente relacionada com a económica e a política. As organizações, portanto, as instituições de saúde também têm seus agentes coletivos articulados por relações de saber, ao lado das relações de produção e das relações de poder. Como 
agentes coletivos, os enfermeiros precisam compreender a dinâmica dessas relações e a força que exercem sobre seu trabalho para melhor lidar com elas e delas participar.

\section{REFERÊNCIAS BIBLIOGRÁFICAS}

ARAUJO, J. D. de Polarizaçåo epidemiológica no Brasil. Inf. Epidem. SUS, n\& 2, p. 5-16, 1992.

MENDES, E. V. O consenso do discurso e o dissenso da prática social: notas sobre a municipalizaçăo da saúde no Brasil. Cadernos da Nona Conferencia Nacional de Saúde, v.1, p. 13-16, 1992.

SANTOS, B. de S. Introdução a uma ciencia pós-modema. 2. ed. Lisboa, Afrontamento, 1990.

SROUR, R. H. Classes, regimes, ideologias. 2. ed. São Paulo, Ática, 1990. 